\title{
Life expectancy, healthy life expectancy, and burden of disease in older people in the Americas, 1990-2019: a population-based study
}

\author{
Ramon Martinez, ${ }^{1}$ Patricia Morsch, ${ }^{1}$ Patricia Soliz, ${ }^{1}$ Carolina Hommes, ${ }^{1}$ Pedro Ordunez, ${ }^{1}$ \\ and Enrique Vega ${ }^{1}$
}

Suggested citation Martinez R, Morsch P, Soliz P, Hommes C, Ordunez P, Vega E. Life expectancy, healthy life expectancy, and burden of disease in older people in the Americas, 1990-2019: a population-based study. Rev Panam Salud Publica. 2021;45:e114. https://doi. org/10.26633/RPSP.2021.114

ABSTRACT

Objective. To describe the life expectancy, healthy life expectancy, disease burden, and leading causes of mortality and disability in adults aged 65 years and older in the Region of the Americas from 1990 to 2019.

Methods. We used estimates from the Global Burden of Disease Study 2019 to examine the level and trends of life expectancy, healthy life expectancy, years of life lost, years lived with disability, and disability-adjusted life years (DALYs).

Results. Across the Region, life expectancy at 65 years increased from 17.1 years (95\% uncertainty intervals (UI): 17.0-17.1) in 1990 to 19.2 years (95\% UI: 18.9-19.4) in 2019 while healthy life expectancy increased from 12.2 years (95\% UI: 10.9-12.4) to 13.6 years (95\% UI: 12.2-14.9). All-cause DALY rates decreased in each older persons' age group; however, absolute proportional DALYs increased from $22 \%$ to $32 \%$. Ischemic heart disease, stroke, and chronic obstructive pulmonary disease were the leading causes of premature mortality. Diabetes mellitus, age-related and other hearing loss, and lower back pain were the leading causes of disability.

Conclusion. The increase in life expectancy and decrease of DALYs indicate the positive effect of improvements in social conditions and health policies. However, the smaller increase in healthy life expectancy suggests that, despite living longer, people spend a substantial amount of time in their old age with disability and illness. Preventable and controllable diseases account for most of the disease burden in older adults in the Americas. Society-wide and life-course approaches, and adequate health services are needed to respond to the health needs of older people in the Region.

Keywords Health of the elderly; mortality; morbidity; Americas.

Living longer has been one of humanity's greatest ambitions, and currently living more than 80 years is a realistic expectation in many countries (1). Life expectancy captures mortality along the entire life course (2) and its improvement is positively associated with welfare and health. In 2019, life expectancy at birth reached 73.3 years globally but with a difference of around 16 years between high-income and low-income countries (3). Moreover, living longer and healthier is essential to achieving the 2030 Agenda for Sustainable Development (4). Certainly, healthy life expectancy indicates how much a country has reduced the incidence, duration, and severity of major diseases. Healthy life expectancy is also strongly associated with socioeconomic level and access to and quality of health care. Life expectancy and healthy life expectancy at 65 years reflect the level of well-being, health, and health care that a given society can offer to those who survive into older adulthood.

\footnotetext{
1 Pan American Health Organization, Washington D.C., United States of

America $\bowtie$ Ramon Martinez, martiner@paho.org
} This is an open access article distributed under the terms of the Creative Commons Attribution-NonCommercial-NoDerivs 3.0 IGO License, which permits use, distribution, and reproduction in any medium, provided the
original work is properly cited. No modifications or commercial use of this article are permitted. In any reproduction of this article there should not be any suggestion that PAHO or this article endorse any specific organization or products. The use of the PAHO logo is not permitted. This notice should be preserved along with the article's original URL. Open access logo and text by PLoS, under the Creative Commons Attribution-Share Alike 3.0 Unported license. 
In 2018, for the first time, people aged 65 years and older outnumbered children under-5 years globally (1). The reductions in highly prevalent infectious diseases, infant mortality and fertility, together with increased human longevity have led to fast population aging. Moreover, rapid urbanization and the increase in unhealthy lifestyles, among other determinants, have accelerated the epidemiological transition and fueled the epidemic of noncommunicable diseases (NCDs) $(5,6)$.

Globally, NCDs accounted for 41.1 million deaths in 2017, representing $73.5 \%$ of total deaths and over $80.0 \%$ of deaths at age 60 years and older. In addition, avoidable NCDs accounted for $83.9 \%$ of all NCD deaths worldwide (7). The effect of NCDs is higher and more extensive in low- and middle-income countries. In 2011, in response to the global NCD epidemic and population aging, the United Nations General Assembly called for countries to tackle NCDs and their risk factors (8). In 2020, the General Assembly declared 2021-2030 the Decade of Healthy Ageing $(9,10)$.

Understanding the magnitude of and trends in the disease burden in older people and the underlying conditions driving those trends is key for designing effective strategies to improve the health of older people, prioritizing interventions, allocating resources and monitoring progress (11). A comprehensive study of the burden of diseases among older people is needed for the Region of the Americas, where the rise in aging populations is accelerating (12). For example, people older than 60 years old make up about $21 \%$ of the total population in Canada and the United States of America (USA), 13\% in the Caribbean, $12 \%$ in South America, and 9\% in Central America (13). Wide social and health disparities accompany this transition, and NCDs are shaping the pattern of morbidity and mortality (14).

This study aimed to describe life expectancy, healthy life expectancy, and burden of diseases in adults aged 65 years and older in the Region of the Americas from 1990 to 2019, and identify the leading causes of mortality and disability to inform programmatic and policy development.

\section{METHODS}

We examined the level, distribution, and trends of life expectancy and healthy life expectancy, and disease burden in older adults aged 65 years and older (65+ years) in the Americas from 1990 to 2019. We used estimates from the 2019 Global Burden of Diseases, Injuries and Risk Factors Study (GBD study) (15). The GBD study is a comprehensive, multinational epidemiological study that estimates disease burden for every country in the world. It is an ongoing effort, updated annually, and is designed to allow consistent comparison over time from 1990 to 2019, by age and sex, and across locations. The study produces standard epidemiological measures such as incidence, prevalence, deaths, and summary measures of health loss for 369 diseases and injuries (16). The 2019 GBD study complies with the Guidelines for Accurate and Transparent Health Estimates Reporting (GATHER) (17). The methods and data sources used in the GBD 2019 have been published elsewhere $(3,15,18)$ and are summarized in the appendix.

\section{Health expectancy and health loss outcome measures and data source}

We examined the level, distribution, and trends of health expectancy measures, including life expectancy, healthy life expectancy, and years of life spent with poor health among people aged 65+ years by age, sex, and location from 1990 to 2019. Life expectancy is the number of years a person is expected to live at any given age. The methods to obtain life expectancy are reported elsewhere (19). Healthy life expectancy is the average number of years of life spent in good health that a person would be expected to live, considering the age-specific mortality and morbidity for a given population in a calendar year $(3,20)$. We calculated years of life spent with poor health, by age, sex, location, and year, by subtracting healthy life expectancy from life expectancy, and the percentage of years of life spent with poor health as years of life spent with poor health as a percentage of life expectancy (i.e. \% of years of life spent with poor health $=$ [life expectancy-healthy life expectancy]/ life expectancy $\times 100$ ). We also analyzed disability-adjusted life years (DALYs), years lived with disabilities (YLDs), and years of life lost (YLLs) due to premature mortality. YLDs represent non-fatal conditions and describe the years lived in less than optimum health, measured as the product of the prevalence estimate and the disability weight for each mutually exclusive condition, corrected for co-morbidities $(15,21)$. YLLs were calculated by multiplying the number of deaths caused by a disease in each age group by the standard life expectancy at that age, regardless of sex (22). The DALY is a summary measure of total health loss, calculated by adding YLDs and YLLs. Total health loss (measured in DALYs) is also referred to as the disease burden. These measures are reported as age-standardized rates and are calculated by the direct method using the world standard population. We extracted mean estimates and $95 \%$ uncertainty interval (UI) for the outcome measures by age, sex, year, and cause for the Region of the Americas, six subregions, and 38 countries and territories (list of countries in the appendix) from the publicly available online GBD results tool (http:/ /ghdx.healthdata.org/gbd-results-tool).

\section{Leading causes of morbidity and mortality}

To determine the underlying disease patterns that affect the burden of disease in older people, we used disease categories at level 3 of the GBD cause list, both fatal and non-fatal conditions, excluding residual categories. We ranked causes of DALYs, YLLs, and YLDs by sex, age group, and location in 2019, and calculated the percentage change from 1990. Because the distribution of causes of DALYs and YLLs are very similar given the large contribution of YLLs to DALYs at older ages, we present the leading causes of premature mortality using YLLs, and disability using YLDs separately.

\section{RESULTS}

\section{Life expectancy and healthy life expectancy at 65 years}

In the Americas, life expectancy at 65 years increased significantly by 2.1 years, from 17.1 years (95\% UI 17.0-17.1) in 1990 to 19.2 years (95\% UI 18.9-19.4) in 2019. Healthy life expectancy at 65 years increased by 1.4 years, from 12.2 years (95\% UI 10.912.4 ) in 1990 to 13.6 years (95\% UI 12.2-14.9) in 2019. However, the percentage of years of life spent with poor health remained about the same: $28.8 \%$ (95\% UI $21.7 \%-35.8 \%$ ) in 1990 and $29.0 \%$ (95\% UI $23.2 \%-35.7 \%$ ) in 2019. Indeed, almost one third of life 
FIGURE 1. Life expectancy and healthy life expectancy at 65 years of age by country and sex, Region of the Americas, 1990 and 2019

\section{Female}

2019, Healthy life expectancy

Bermuda

Puerto Rico

Panama

Canada

Colombia

Costa Rica

Peru

United States of America

Chile

REGION OF THE AMERICAS

El Salvador

Uruguay

Paraguay

Brazil

Cuba

Venezuela (Bolivarian Republic of)

Belize

Jamaica

Argentina

Mexico

Saint Lucia

Trinidad and Tobago

Ecuador

Bahamas

Dominican Republic

Suriname

United States Virgin Islands

Barbados

Nicaragua

Guatemala

Antigua and Barbuda

Dominica

Saint Vincent and the Grenadines

Grenada

Saint Kitts and Nevis

Honduras

Bolivia (Plurinational State of)

Guyana

Haiti

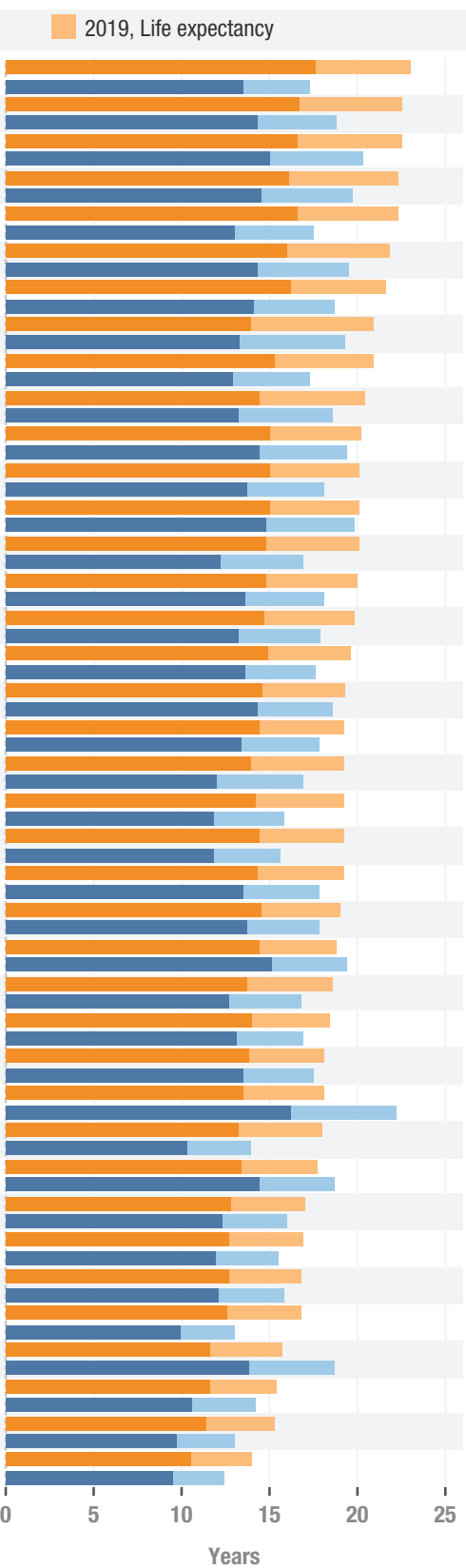

Years

5

Male

1990, Healthy life expectancy

Peru

Colombia

Panama

Puerto Rico

Canada

Costa Rica

Chile

United States of America

REGION OF THE AMERICAS

Bermuda

Ecuador

El Salvador

Mexico

Cuba

Brazil

Belize

Paraguay

Jamaica

Guatemala

Venezuela (Bolivarian Republic of)

Barbados

Antigua and Barbuda

Trinidad and Tobago

Uruguay

Dominican Republic

Bahamas

Saint Lucia

Suriname

Argentina

Saint Vincent and the Grenadines

Bolivia (Plurinational State of)

Nicaragua

Dominica

Honduras

United States Virgin Islands

Grenada

Haiti

Saint Kitts and Nevis

Guyana
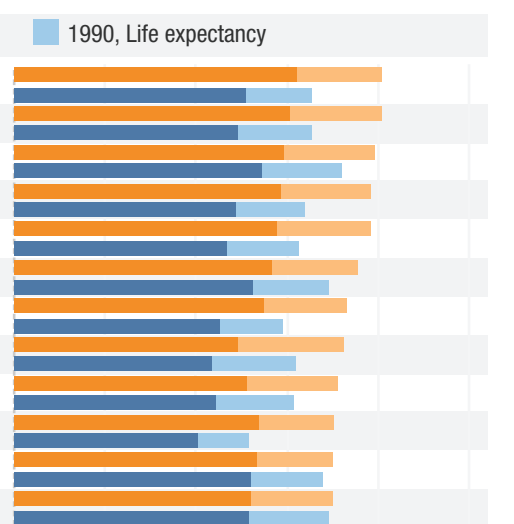

Source: Based on results obtained from the analysis of estimates from the Global Burden of Disease Study 2019. Countries are presented in descending order of rates of disability-adjusted life years (DALY) per 100000 population in 2019 in each sex separately. The combination of life expectancy measures and years is color-coded as presented in the legend.

expectancy is spent in poor health, with the gradient increasing with age. Life expectancy and healthy life expectancy increased in all subregions and the percentage of years of life spent with poor health remained constant, except in Central Latin America where it decreased, particularly at $85+$ years (Table S1 and Figure S1 in the appendix). Table S1, panel A in the appendix shows a similar analysis for life expectancy and healthy life expectancy at birth.

Between 1990 and 2019, life expectancy at 65 years substantially decreased in Antigua and Barbuda, the Dominican
Republic, Honduras, and Nicaragua for women, and the Dominican Republic, Honduras, Nicaragua, Paraguay, and the US Virgin Islands for men (Figure 1). In 2019, substantial disparities persisted across countries in both life expectancy and healthy life expectancy (Figure 1). Life expectancy and healthy life expectancy at 65 years increased in seven countries (Bolivia, Brazil, Colombia, Costa Rica, Mexico, Paraguay and Venezuela) for women and in four countries (Brazil, Colombia, Mexico and Venezuela) for men. However, in most countries, life expectancy increased but healthy life expectancy decreased. 
Life expectancy declined and healthy life expectancy increased in only two countries (Nicaragua and Honduras) for women. Both life expectancy and healthy life expectancy declined in two countries for women (Dominican Republic and Antigua and Barbuda) and in six countries for men (Belize, Dominican Republic, Honduras, Nicaragua, Paraguay, and United States Virgin Islands) (Figure S2 in the appendix)

\section{Burden of disease}

From 1990 to 2019, all-cause DALY rates at 65-69 years decreased in most countries except in: Dominican Republic, Honduras, Nicaragua, and Paraguay for both men and women; Antigua and Barbuda for women; and Belize and US Virgin Islands for men (Figure 2). Among countries with DALY rates

FIGURE 2. Burden of disease measured by rates of disability-adjusted life years (DALY) per 100000 population in people aged 65-69 years, broken down as years of life lost and years lived with disability by country and sex, Region of the Americas, 1990 and 2019

1990, Years of life lost

1990, Years lived with disability

\section{Female}

\begin{tabular}{|c|}
\hline Haiti \\
\hline Guyana \\
\hline Honduras \\
\hline Bolivia (Plurinational State of) \\
\hline Grenada \\
\hline Guatemala \\
\hline Saint Kitts and Nevis \\
\hline Dominica \\
\hline Saint Vincent and the Grenadines \\
\hline Suriname \\
\hline Antigua and Barbuda \\
\hline Trinidad and Tobago \\
\hline Mexico \\
\hline Bahamas \\
\hline Jamaica \\
\hline Barbados \\
\hline Nicaragua \\
\hline Saint Lucia \\
\hline Belize \\
\hline Venezuela (Bolivarian Republic of) \\
\hline United States Virgin Islands \\
\hline Dominican Republic \\
\hline El Salvador \\
\hline Paraguay \\
\hline Cuba \\
\hline United States of America \\
\hline REGION OF THE AMERICAS \\
\hline Brazil \\
\hline Argentina \\
\hline Ecuador \\
\hline Uruguay \\
\hline Chile \\
\hline Peru \\
\hline Panama \\
\hline Costa Rica \\
\hline Colombia \\
\hline Puerto Rico \\
\hline Canada \\
\hline Bermuda \\
\hline
\end{tabular}

2019, Years of life lost

2019, Years lived with disability

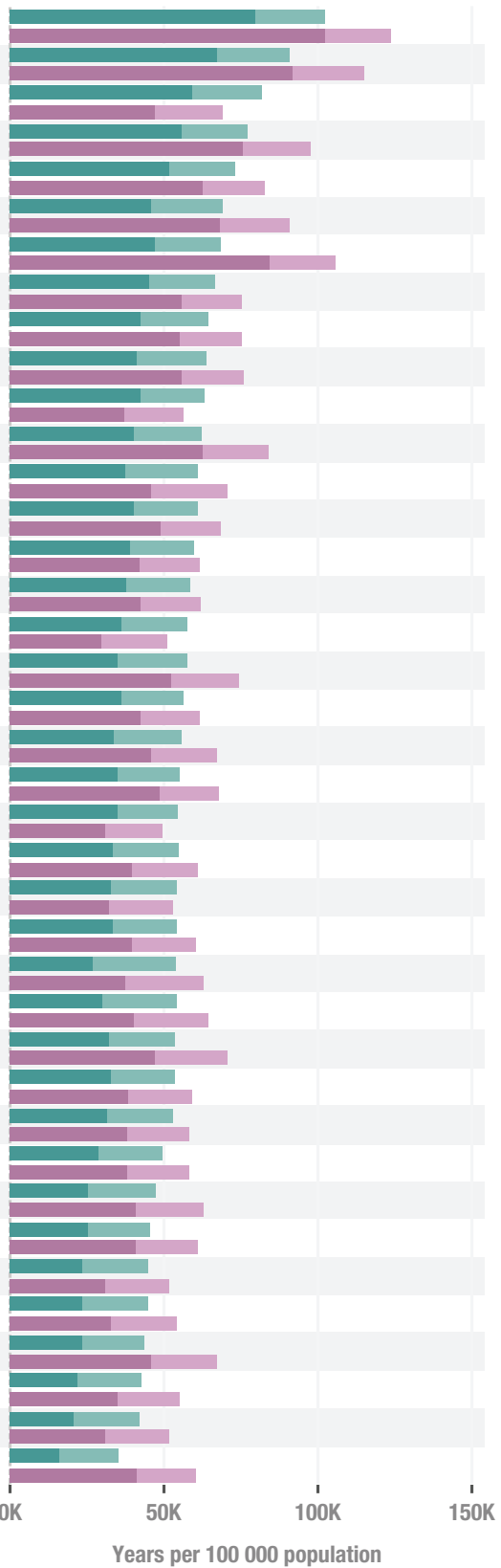

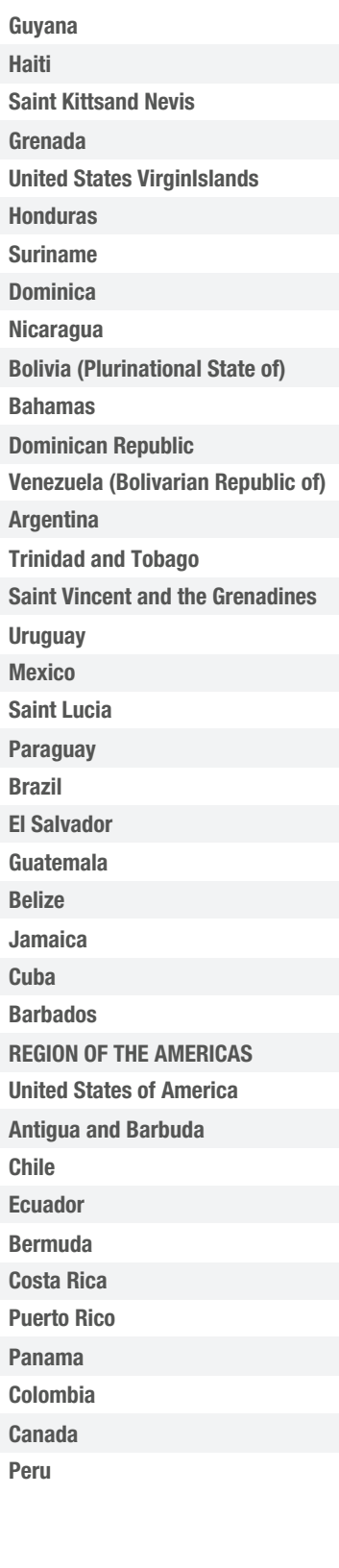

\section{Male}

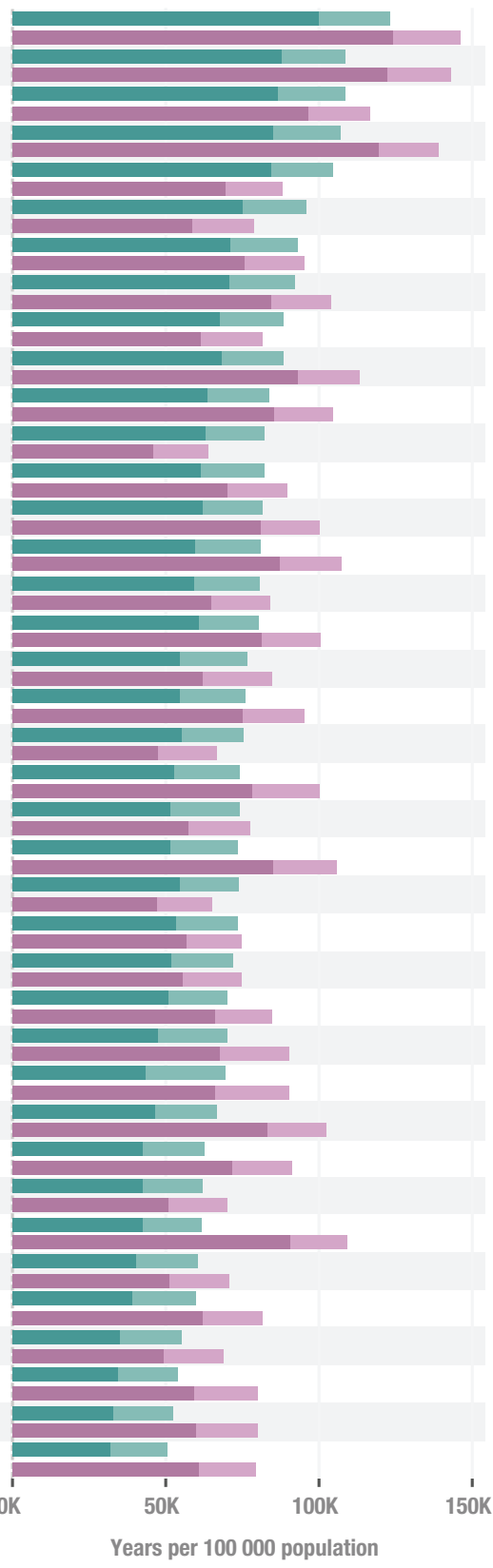

Source: Based on results obtained from the analysis of estimates from the Global Burden of Disease Study 2019. Countries are presented in descending order of DALY rates per 100 000 population in 2019 in each sex separately. 
higher than the regional rate, there are countries with large populations such as Mexico and the USA, high-income countries such as Barbados and Trinidad and Tobago, and Caribbean and Central American countries (Figure 2). In this period, the proportion of all-cause DALYs increased from $22 \%$ to $32 \%$ in people aged 65 years and over (Figure S3 in the appendix) showing a shift towards old ages, while age-standardized DALY rates for all causes decreased in each older persons' age group (Figure S4 in the appendix). Figure S4 shows the time trends of agestandardized DALY rates for all causes in both sexes combined at regional and national levels, respectively.

\section{Premature mortality}

Premature mortality is consistently higher in men than women with large differences across countries. YLL rates in people aged 65-69 years in both sexes combined vary from 83503 years (95\% UI 66 227-109 021) in Haiti to 26703 years (95\% UI 26 345-27 079) in Canada (Figure 2). Most countries have a decreasing or constant trend over time in age-specific YLL rates from all causes of mortality, in both sexes in older people; however, six countries (Dominican Republic, Honduras, Nicaragua, Paraguay, Saint Lucia, and Saint Vincent and the Grenadines) have an increasing trend. Regionally, the gradient in premature mortality due to all causes in older adults increases with age, however, with a decreasing time trend at each age regardless of sex (Figure S5, S6, and Table S2 in the appendix).

In the Americas in 2019, the leading causes of premature mortality among people aged 65+ years for both sexes combined were ischaemic heart disease, stroke, and chronic obstructive pulmonary disease. Lung cancer, chronic kidney disease, prostate cancer, and diabetes mellitus ranked fourth to seventh for men (Figure 3, panel A), and Alzheimer disease and other dementias, and diabetes mellitus ranked fourth and fifth for women, followed by lung cancer, chronic kidney disease, lower respiratory infections, and breast cancer (Figure 3, panel B). Cirrhosis and other chronic liver diseases, and colon and rectum cancer are among the top 20 causes of premature mortality for each sex. From 1990 to 2019, a few changes were observed in the ranking of causes of YLLs due to premature death: chronic kidney disease moved up from tenth to fifth position in men and from tenth to seventh in women, Alzheimer disease and other dementias moved up from twelfth to ninth position in men and from sixth to fourth in women, while falls moved up from 19th position to 14th in women (Figure 3, panels A and B). Parkinson disease, urinary disease, and atrial fibrillation and flutter emerged among the top 20 causes of premature mortality in both sexes combined (Figure S7 in the appendix).

By country, age, and sex in 2019, ischemic heart disease, stroke, diabetes mellitus, hypertensive heart disease, and chronic kidney disease were the leading causes of YLL. In addition, prostate cancer in men, breast cancer in women, and tracheal, bronchus and lung cancer in both sexes were also leading causes (Figure 4, Figure S8 in the appendix).

\section{Disability}

The burden of disability in older people increased with age and over time; however, YLD per population remained constant or increased slightly in each age group regardless of sex
(Figure S9 in the appendix). Between 1990 and 2019, all-cause YLD per 100000 population for both sexes combined ranged from 23294 years (95\% UI 17 640-29 636) to 23351 years (95\% UI 17 645-29 734) among people aged 65-69 years, and from 36489 years (95\% UI $27879-45825)$ to 37134 years (95\% UI 28 444-46 390) per 100000 population among people aged 85 years and older. No differences were observed in the level and trends in YLD by sex (Table S2 and Figure S10 in the appendix). In 2019, YLDs in both sexes combined varied across all countries in the Region, from 26070 years (95\% UI 19 823-32 722) in the USA to 18952 years (95\% UI 14 133-24 475) in Bermuda (Figure 2, Table S2 in the appendix).

In 2019, most of the leading causes of YLDs among older people were NCDs, but two injuries (falls, and road injuries) were also among the leading causes. The pattern of causes of YLDs in 1990 and 2019 remained constant. In 2019, diabetes mellitus, age-related hearing loss, lower back pain, osteoarthritis, chronic obstructive pulmonary disease, and falls were the top six causes of YLD for men and women (Figure 5). Between 1990 and 2019 in both sexes, diabetes mellitus moved up from third position as a cause of YLD to first. In men, diabetes mellitus, falls, Alzheimer disease and other dementias, neck pain, depressive disorders, and chronic kidney disease all moved up (chronic kidney disease climbed four positions). In women, diabetes mellitus, falls, Alzheimer disease and other dementias, and chronic kidney disease all moved up (Figure 5, Figure S11 in the appendix).

In 2019, diabetes mellitus, and age-related and other hearing loss ranked first and second as causes of disability in most countries in both sexes and all age groups 65 years and older. Lower back pain, and blindness and vision loss were also common in most countries and in most age groups (Figure 6, Figure S12 in the appendix).

Life expectancy and YLL in older people had a significant negative association across countries - if YLL increased, then life expectancy decreased - and the values in both measures decreased with age. The percentage of years of life spent with poor health and YLD rates were positively associated at all ages and in both sexes. The values of both measures increased with age and both measures varied substantially across countries (Figure S13 in the appendix).

\section{DISCUSSION}

The Decade of Healthy Ageing is an opportunity to address the health of older adults. Improvement and maintenance of functional ability through strategies to reduce risk factors and provide high-quality health services to prevent and manage NCDs is essential (23). Health at older ages does not mean being disease-free. Instead, healthy aging in the presence of diseases reflects a focus on living well and optimizing functional ability, with the understanding that NCDs can substantially affect an individual's mental and physical capacities (23).

In the Region of the Americas, age-standardized DALY rates from all causes in the total population decreased over time; however, the distribution of disease burden is shifting to older ages. The consistent decreasing time trends in DALY rates among older people at each age are the result of a substantial reduction in premature mortality, mainly from cardiovascular diseases, the leading cause of death in most countries of the Americas (24). However, a recent study suggests that the 
FIGURE 3. Leading causes of years of life lost due to premature mortality among older people (aged 65 years and older) by sex, Region of the Americas, 1990 and 2019

Males

1990

\begin{tabular}{|l|}
\hline 1 Ischemic heart disease \\
\hline 2 Stroke \\
\hline 3 Tracheal, bronchus, and lung cancer \\
\hline 4 Chronic obstructive pulmonary disease \\
5 Prostate cancer \\
6 Lower respiratory infections \\
\hline 7 Diabetes mellitus \\
\hline 8 Colon and rectum cancer \\
\hline 9 Cirrhosis and other chronic liver diseases \\
\hline 10 Chronic kidney disease \\
\hline 11 Stomach cancer \\
\hline 12 Alzheimer disease and other dementias \\
\hline 13 Hypertensive heart disease \\
\hline 14 Cardiomyopathy and myocarditis \\
\hline 15 Pancreatic cancer \\
\hline 16 Road injuries \\
\hline 17 Aortic aneurysm \\
\hline 18 Esophageal cancer \\
\hline 19 Bladder cancer \\
\hline 20 Leukemia \\
\hline
\end{tabular}

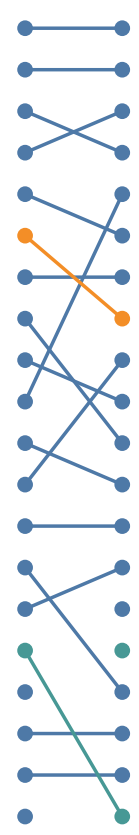

2019

\begin{tabular}{|l|}
\hline 1 Ischemic heart disease \\
\hline 2 Stroke \\
\hline 3 Chronic obstructive pulmonary disease \\
4 Tracheal, bronchus, and lung cancer \\
5 Chronic kidney disease \\
6 Prostate cancer \\
7 Diabetes mellitus \\
8 Lower respiratory infections \\
\hline 9 Alzheimer disease and other dementias \\
10 Cirrhosis and other chronic liver diseases \\
11 Colon and rectum cancer \\
12 Stomach cancer \\
\hline 13 Hypertensive heart disease \\
14 Pancreatic cancer \\
15 Parkinson disease \\
16 Falls \\
\hline 17 Cardiomyopathy and myocarditis \\
18 Esophageal cancer \\
\hline 19 Bladder cancer \\
\hline 20 Road injuries \\
\hline
\end{tabular}

Females

1990

\begin{tabular}{|l|}
\hline 1 Ischemic heart disease \\
\hline 2 Stroke \\
\hline 3 Chronic obstructive pulmonary disease \\
\hline 4 Diabetes mellitus \\
\hline 5 Tracheal, bronchus, and lung cancer \\
\hline 6 Alzheimer disease and other dementias \\
\hline 7 Lower respiratory infections \\
\hline 8 Breast cancer \\
\hline 9 Colon and rectum cancer \\
\hline 10 Chronic kidney disease \\
\hline 11 Hypertensive heart disease \\
\hline 12 Cirrhosis and other chronic liver diseases \\
\hline 13 Stomach cancer \\
\hline 14 Pancreatic cancer \\
\hline 15 Ovarian cancer \\
\hline 16 Cardiomyopathy and myocarditis \\
\hline 17 Cervical cancer \\
\hline 18 Non-Hodgkin lymphoma \\
\hline 19 Falls \\
\hline 20 Atrial fibrillation and flutter \\
\hline
\end{tabular}

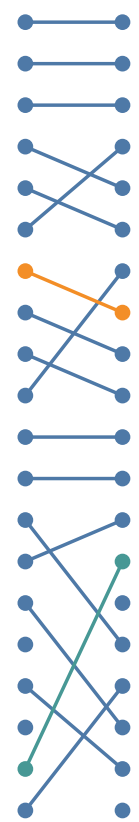

Source: Based on results obtained from the analysis of estimates from the Global Burden of Disease Study 2019. Causes are color-coded by Level 1 cause category of the Global Burden of Disease Study - orange: maternal, neonatal and communicable diseases; blue: noncommunicable diseases; and green: injury.

decline in premature mortality from cardiovascular diseases has plateaued and even started to increase in the most populated countries of the Region, including the USA and Canada which had previously achieved the most significant reductions (25). This observation is of concern because of the potential effect of the cardiovascular disease burden on life expectancy and healthy life expectancy, especially in people aged 65+ years in the years to come.

In terms of causes of premature mortality, chronic kidney disease, which has shown the highest increase since 1990, deserves 
special attention. People with chronic kidney disease require specialized and costly health care services. Furthermore, chronic kidney disease is largely preventable, so more efforts are needed to reduce its risk factors and improve care $(26,27)$. Regionally, the disparity in premature mortality between countries, e.g. mortality from cardiovascular disease (25), has also been substantially reduced. This reduction seems to be associated with a general improvement in the level of economic development and access to and quality of health services. However, it is alarming that some countries with relatively good economic performance in the past decade, such as the Dominican Republic, have shown a decline in life expectancy and an increase in the DALY rate among older people. This decline should be further investigated to understand the potential causes.

The lower rate of increase of healthy life expectancy than life expectancy at 65 years of age in the past three decades means that people are living longer but are spending more of their life time with disabilities and illness. The disability burden revealed underlying conditions that accounted for years of life spent with illness. These conditions ultimately affect quality of life, increase dependence on care, limit the social contribution and opportunities of people of old age (28), and increase the burden on the family and the health system. This finding highlights the importance of providing timely strategies to prevent disability associated with chronic diseases as populations are living longer. In addition, it indicates the urgent need to provide age-disaggregated data in the older adult population and address the oldest age group as a specific group for interventions and research (23).

Diabetes mellitus was the leading cause of YLDs for older people in each age group across countries of the Region in 2019. However, diabetes mellitus is a preventable condition, which

FIGURE 4. Leading causes of premature mortality by country, age group, and sex, Region of the Americas, 2019

Males

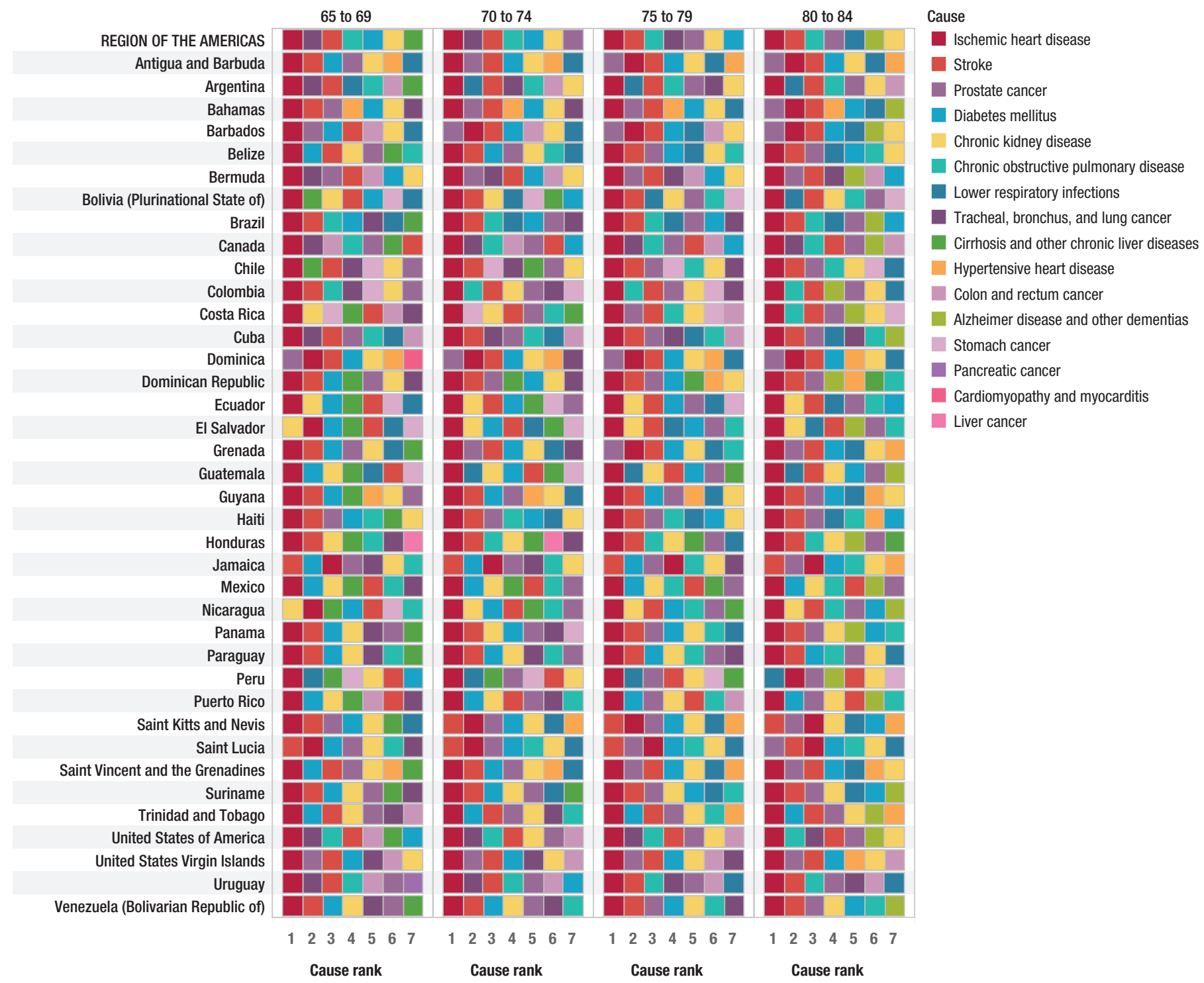




\section{Females}

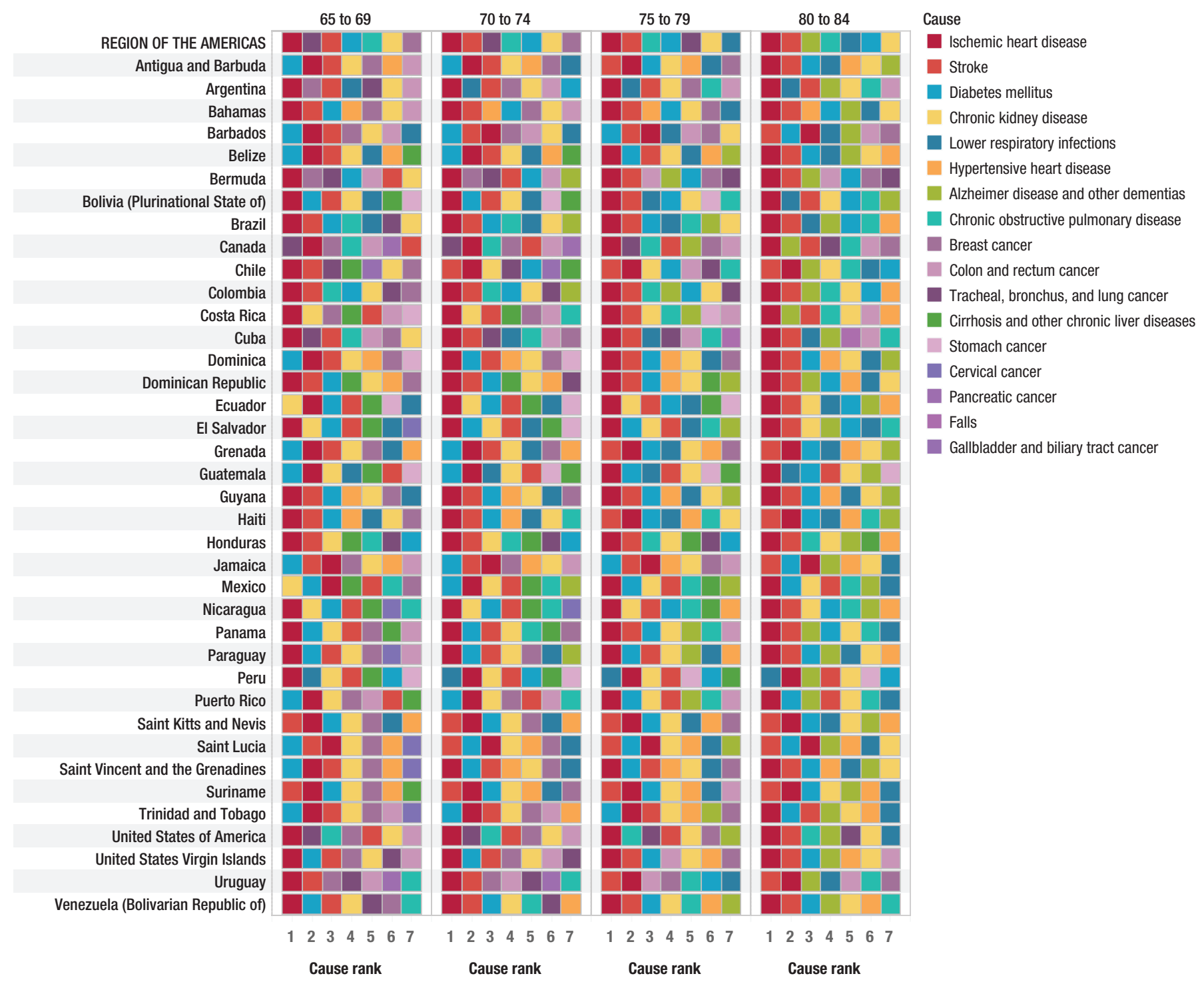

Source: Based on results obtained from the analysis of estimates from the Global Burden of Disease Study 2019.

is strongly associated with obesity and the obesogenic environment before 65 years. It is also a very manageable clinical condition with good access to and quality of care at all ages, including older ages (29). Indeed, hypertension control combined with cardiovascular disease secondary prevention, which are comprehensive and cost-effective clinical interventions, are still poorly implemented across the world but have enormous potential to reduce both the cardiovascular disease and diabetes mellitus burdens $(30,31)$.

Apart from the effects of healthy behaviors and personal lifestyle in preventing and managing the main NCDs, physical activity can provide a wide range of improvements in the health of older adults and prevent losses in functional ability (32). For example, falls, a leading cause of disability among older adults in our study, can be reduced by promoting physical activity in a safe environment, especially activities that target different areas (strength, balance and functional exercises) (33).

Age-related and other hearing loss was the second leading cause of disability in our study, which is consistent with other studies (34). Older people with hearing loss are likely to benefit from timely clinical attention, rehabilitation services, and interventions such as hearing aids (35). Sensory health, including hearing and vision capacities, is one of the main domains of intrinsic capacity (physical and mental capacities that an individual can draw on at any point in their life) (36), which is a fundamental aspect of healthy aging.

The burden of disability in older adults, characterized by the presence of more than one chronic condition (multimorbidity) and polypharmacy, together with accelerated aging and the epidemiological transition towards NCDs, pose new health 
FIGURE 5. Leading causes of years lived with disability among older people (aged 65 years and older) by sex, Region of the Americas, 1990 and 2019

Male

1990

\begin{tabular}{|l|l|}
\hline 1 Age-related and other hearing loss \\
\hline 2 Low back pain \\
\hline 3 Diabetes mellitus \\
\hline 4 Chronic obstructive pulmonary disease \\
\hline 5 Osteoarthritis \\
\hline 6 Oral disorders \\
\hline 7 Falls \\
\hline 8 Blindness and vision loss \\
\hline 9 Stroke \\
\hline 10 Alzheimer disease and other dementias \\
\hline 11 Atrial fibrillation and flutter \\
\hline 12 Ischemic heart disease \\
\hline 13 Neck pain \\
\hline 14 Depressive disorders \\
\hline 15 Prostate cancer \\
\hline 16 Exposure to mechanical forces \\
\hline 17 Road injuries \\
\hline 18 Chronic kidney disease \\
\hline 19 Endocrine, metabolic, blood, and immune disorders \\
\hline 20 Asthma \\
\hline
\end{tabular}

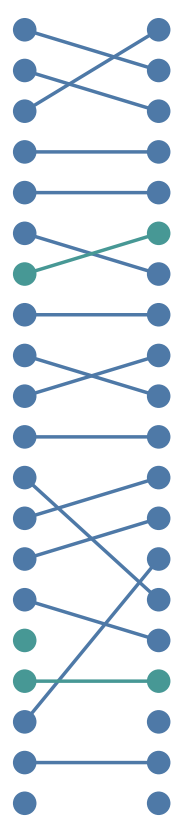

2019

\begin{tabular}{|l|}
\hline 1 Diabetes mellitus \\
\hline 2 Age-related and other hearing loss \\
\hline 3 Low back pain \\
4 Chronic obstructive pulmonary disease \\
\hline 6 fteoarthritis \\
7 Orlls \\
\hline 8 Blindness and vision loss \\
9 Alzheimer disease and other dementias \\
10 Stroke \\
11 Atrial fibrillation and flutter \\
12 Neck pain \\
13 Depressive disorders \\
14 Chronic kidney disease \\
15 Ischemic heart disease \\
16 Prostate cancer \\
17 Road injuries \\
18 Urinary diseases and male infertility \\
19 Endocrine, metabolic, blood, and immune disorders \\
\hline 20 Anxiety disorders \\
\hline
\end{tabular}

Female

1990

\begin{tabular}{|l|}
\hline 1 Low back pain \\
\hline 2 Age-related and other hearing loss \\
\hline 3 Diabetes mellitus \\
\hline 4 Osteoarthritis \\
\hline 5 Chronic obstructive pulmonary disease \\
6 Stroke \\
\hline 7 Oral disorders \\
\hline 8 Falls \\
\hline 9 Alzheimer disease and other dementias \\
\hline 10 Blindness and vision loss \\
\hline 11 Depressive disorders \\
\hline 12 Neck pain \\
\hline 13 Endocrine, metabolic, blood, and immune disorders \\
\hline 14 Anxiety disorders \\
\hline 15 Headache disorders \\
\hline 16 Atrial fibrillation and flutter \\
\hline 17 Asthma \\
\hline 18 Chronic kidney disease \\
\hline 19 Ischemic heart disease \\
\hline 20 Gynecological diseases \\
\hline
\end{tabular}

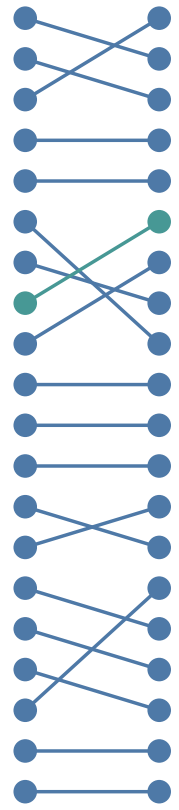

2019

\begin{tabular}{|l|}
\hline 1 Diabetes mellitus \\
2 Low back pain \\
3 Age-related and other hearing loss \\
4 Osteoarthritis \\
5 Chronic obstructive pulmonary disease \\
6 Falls \\
7 Alzheimer disease and other dementias \\
8 Oral disorders \\
9 Stroke \\
10 Blindness and vision loss \\
11 Depressive disorders \\
12 Neck pain \\
13 Anxiety disorders \\
14 Endocrine, metabolic, blood, and immune disorders \\
15 Chronic kidney disease \\
16 Headache disorders \\
17 Atrial fibrillation and flutter \\
18 Asthma \\
19 Ischemic heart disease \\
20 Gynecological diseases \\
\hline
\end{tabular}

Source: Based on results obtained from the analysis of estimates from the Global Burden of Disease Study 2019. Causes are color-coded by Level 1 Global Burden of Disease cause category - blue: noncommunicable diseases; green: injury. Any cause from the GBD cause group I Maternal, neonatal and communicable diseases ranked 20th in causes of years lived with disability.

challenges. These factors lead to complex clinical situations that require: innovative health systems; health care capacities to tackle multimorbidity, rather than the single health condition approach; primary health services that are responsive to older people and inter-related with new community roles; and improved access to long-term care for all people who need it (36). The burden of multimorbidity in older people in the Americas should be explored in further studies to guide policy development. 
A life-course approach suggests that healthy behavior and lifestyles, access to affordable and good-quality health care, and life opportunities during adulthood can help maintain intrinsic capacities and functional ability after peak capacity has been reached (37). Efforts to improve healthy life expectancy should focus on: building and maintaining intrinsic capacity earlier in life, as its decline is associated with underlying conditions and morbidities, including frailty; reducing time spent in ill-health; and improving older adults' intrinsic capacity and functional ability (23). A better understanding of how to implement preventive interventions, including self-management, and design sustainable and essential health services for different periods of the life course is needed.

Limitations related to the GBD methodology and data sources for disease burden estimation are described elsewhere $(3,15)$. A limitation of our study is the under-registration and incomplete medical certification of cause of death in the vital statistics systems of some countries. Moreover, population-based data for morbidity by condition and sequelae are generally insufficient or unavailable for many countries. Estimates for countries with missing or limited data are modeled in the GBD but are of lower reliability than data collected through robust surveillance and vital registration systems, which may explain the large uncertainty for YLD estimates. For morbidity, the GBD study systematically collects all available sources of data, applies standard methods to improve data utility and provide sound estimates. For mortality data, the GBD study addresses these limitations by evaluating data quality. In particular, the GBD study estimates the completeness of death registration, quantifies the proportion of cause-of-death coded as "garbage codes", applies standard data corrections and adjustments to overcome data incompleteness, and uses death distribution methods to improve the value of underlying cause of death for public health.

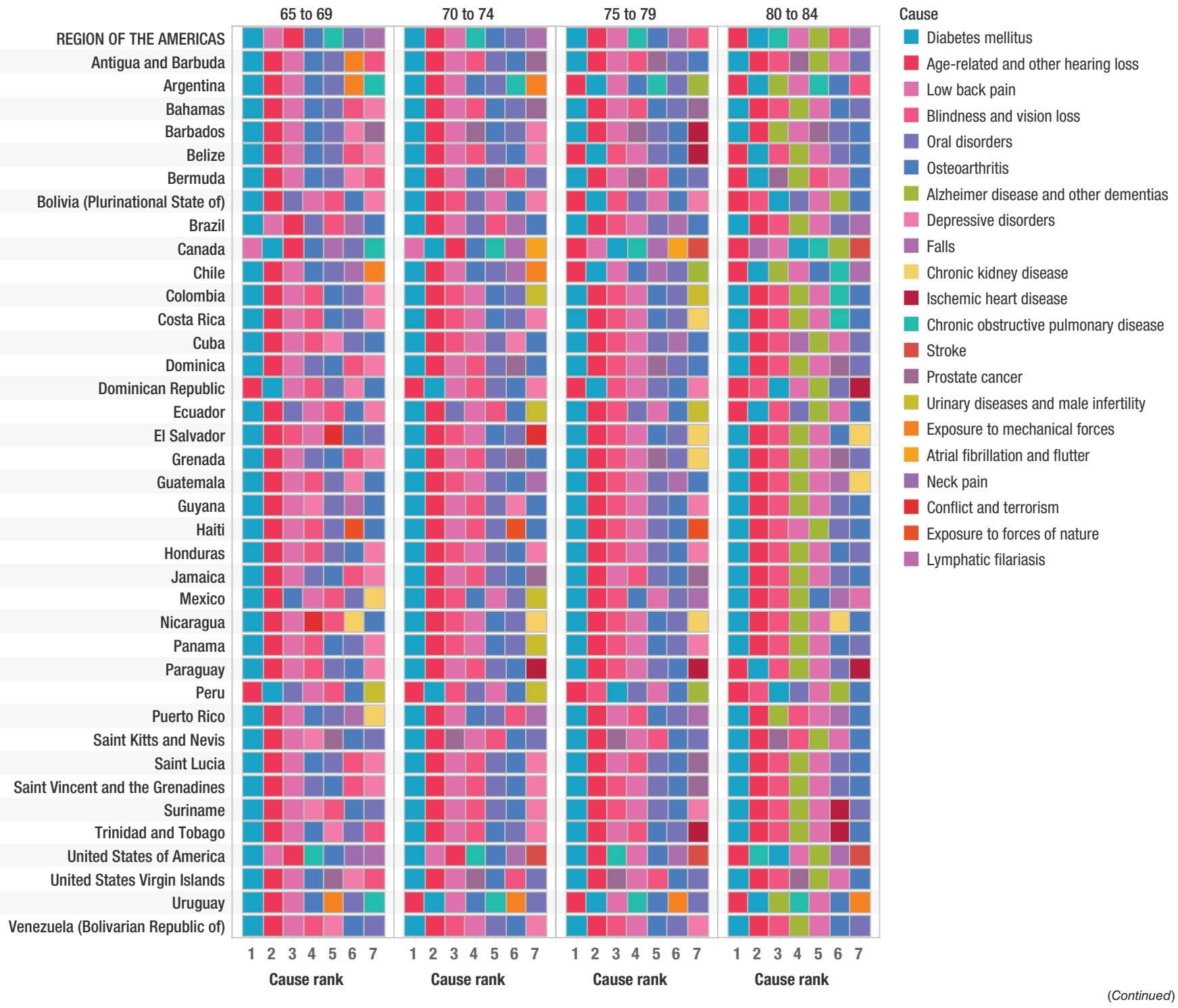




\section{Female}

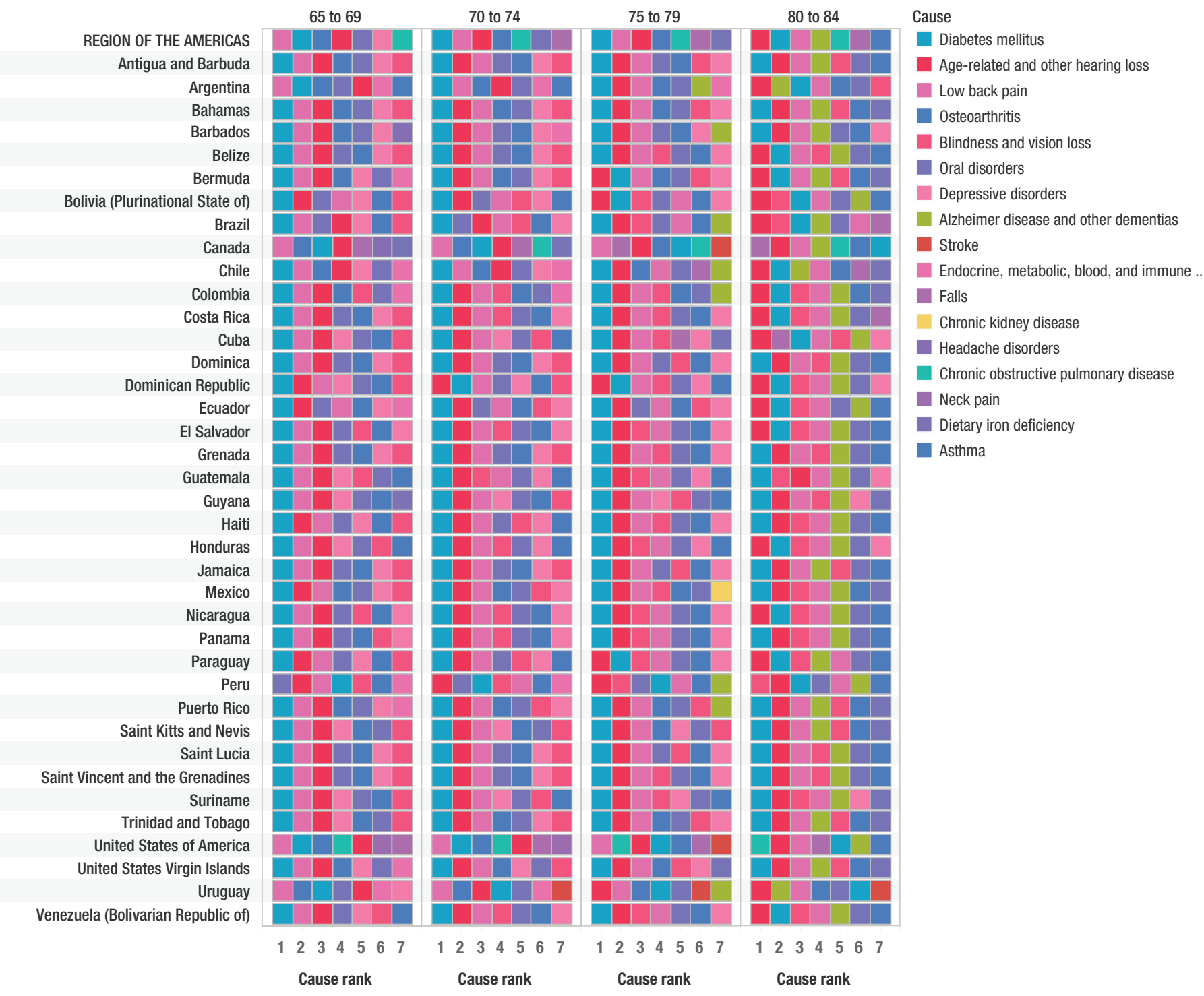

Source: Based on results obtained from the analysis of estimates from the Global Burden of Disease Study 2019.

In conclusion, the increase in life expectancy and healthy life expectancy at 65 years and decrease of DALY rates in old people over the past three decades in the Americas are probably the result of economic and social progress, the success of public health policies, and improvements in disease prevention and access to and quality of care. However, the small increase in healthy life expectancy relative to the increase in life expectancy shows that, despite living longer, people spend a substantial amount of their old age with disability and illness, which negatively affect their quality of life, increase the burden of care dependency and limit their social contribution.

Despite the decline in disease burden rates among old people in all age groups 65 years and older, its distribution is shifting toward the more older people. Aging and greater longevity are leading to a situation of increased morbidity and disability at old ages.
Preventable or potentially controllable diseases throughout the lifespan are responsible for most of the burden of disease among older people in the Americas. Society-wide and lifecourse approaches, health investment, and adequate health services are needed to respond to the new health needs of older people, which is critical to achieving the 2030 Agenda for Sustainable Development and for the Decade of Healthy Aging.

Availability of data and materials. Data and supplementary materials are available from the corresponding author upon request.

Authors' contributions. RM and EV conceived the original research idea and led the design of the study. RM collected the data and conducted the analysis. All authors participated in the interpretation of the findings. Each author contributed 
important intellectual content during the preparation and revision of the manuscript. All authors accept accountability for the overall work.

Conflict of interest. None declared.
Disclaimer. The authors are solely responsible for the views expressed in the manuscript, which may not necessarily reflect the opinion or policy of the Revista Panamericana de Salud Pública/Pan American Journal of Public Health and/or those of the Pan American Health Organization.

Funding. None.

\section{REFERENCES}

1. United Nations Department of Economic and Social Affairs. World population ageing 2019. New York: United Nations; 2020.

2. Murray CJL, Salomon JA, Mathers CD, Lopez AD, editors. Summary measures of population health: concepts, ethics, measurement and applications. Geneva: World Health Organization; 2002.

3. Wang H, Abbas KM, Abbasifard M, Abbasi-Kangevari M, Abbastabar H, Abd-Allah F, et al. Global age-sex-specific fertility, mortality, healthy life expectancy (HALE), and population estimates in 204 countries and territories, 1950-2019: a comprehensive demographic analysis for the Global Burden of Disease Study 2019. Lancet. 2020;396(10258):1160-203.

4. United Nations Department of Economic and Social Affairs. Transforming our world: the 2030 Agenda for Sustainable Development [Internet]. New York: United Nations; 2015 [cited 2021 Feb 27]. Available from: https://sdgs.un.org/2030agenda

5. World Health Organization. Noncommunicable diseases. Key facts [Internet]. Geneva: World Health Organization; 2018 [cited 2021 Mar 22]. Available from: https://www.who.int/news-room/ fact-sheets/detail/noncommunicable-diseases

6. World Health Organization. World report on ageing and health. Geneva: World Health Organization; 2015.

7. Martinez R, Lloyd-Sherlock P, Soliz P, Ebrahim S, Vega E, Ordunez $\mathrm{P}$, et al. Trends in premature avertable mortality from non-communicable diseases for 195 countries and territories, 19902017: a population-based study. Lancet Glob Heal. 2020;8(4):e511-23.

8. United Nations. Political Declaration of the High-level Meeting of the General Assembly on the Prevention and Control of Noncommunicable Diseases. New York: United Nations; 2011.

9. United Nations. Resolution A/RES/75/13. Decade of Healthy Ageing (2021-2030) [Internet]. 75th General Assembly. New York: United Nations; 2020 [cited 2021 Feb 27]. Available from: https:// undocs.org/en/A/RES/75/131

10. World Health Organization. UN Decade of Healthy Ageing [Internet]. World Health Organization [cited $2021 \mathrm{Feb} 27]$. Available from: https:/ / www.who.int/ageing/decade-of-healthy-ageing

11. Michel JP, Sadana R. "Healthy Aging" concepts and measures. Am Med Dir Assoc. 2017;18(6):460-4.

12. United Nations Department of Economic and Social Affairs. World population prospects 2019 [Internet]. New York: United Nations; 2019 [cited 2021 Feb 27]. Available from: https://population. un.org/wpp/

13. Pan American Health Organization. Aging and demographic changes. In: Health in the Americas 2017 [Internet]. Washington D.C.: Pan American Health Organization; 2018 [cited 2021 Feb 28]. Available from: https://www.paho.org/salud-en-las-americas$2017 / ? \mathrm{p}=55$

14. Pan American Health Organization. Health in the Americas+, 2017 edition. Summary: regional outlook and country profiles. Washington D.C.: Pan American Health Organization; 2017:260.

15. Abbafati C, Machado DB, Cislaghi B, Salman OM, Karanikolos M, McKee M, et al. Global burden of 369 diseases and injuries in 204 countries and territories, 1990-2019: a systematic analysis for the Global Burden of Disease Study 2019. Lancet. 2020;396(10258): 1204-22.

16. Institute of Health Metrics and Evaluation. Global Burden of Disease Study 2019 (GBD 2019). Cause list mapped to ICD codes [Internet]. Seattle, WA: Institute of Health Metrics and Evaluation; 2020 [cited 2021 Feb 27]. Available from: http://ghdx.healthdata. org/record/ihme-data/gbd-2019-cause-icd-code-mappings
17. Stevens GA, Alkema L, Black RE, Boerma JT, Collins GS, Ezzati $\mathrm{M}$, et al. Guidelines for accurate and transparent health estimates reporting: the GATHER statement. Lancet. 2016;388(10062):e19-e23.

18. Vollset SE, Goren E, Yuan CW, Cao J, Smith AE, Hsiao T, et al. Fertility, mortality, migration, and population scenarios for 195 countries and territories from 2017 to 2100: a forecasting analysis for the Global Burden of Disease Study. Lancet. 2020;396(10258): 1285-306.

19. Dicker D, Nguyen G, Abate D, Abate KH, Abay SM, Abbafati C, et al. Global, regional, and national age-sex-specific mortality and life expectancy, 1950-2017: a systematic analysis for the Global Burden of Disease Study 2017. Lancet. 2018;392(10159):1684-735.

20. GBD 2017 DALYs and HALE Collaborators. Global, regional, and national disability-adjusted life-years (DALYs) for 359 diseases and injuries and healthy life expectancy (HALE) for 195 countries and territories, 1990-2017: a systematic analysis for the Global Burden of Disease Study 2017. Lancet. 2018;392(10159):1859-922.

21. James SL, Abate D, Abate KH, Abay SM, Abbafati C, Abbasi N, et al. Global, regional, and national incidence, prevalence, and years lived with disability for 354 diseases and injuries for 195 countries and territories, 1990-2017: a systematic analysis for the Global Burden of Disease Study 2017. Lancet. 2018;392(10159):1789-858.

22. Martinez R, Soliz P, Caixeta R, Ordunez P. Reflection on modern methods: years of life lost due to premature mortality-a versatile and comprehensive measure for monitoring non-communicable disease mortality. Int J Epidemiol. 2019;48(4):1367-76.

23. World Health Organization. Decade of healthy ageing: baseline report. Geneva: World Health Organization; 2020:220.

24. Lloyd-Sherlock P, Ebrahim S, Martinez R, McKee M, Ordunez P. Reducing the cardiovascular disease burden for people of all ages in the Americas region: analysis of mortality data, 2000-15. Lancet Glob Heal. 2019;7(5):e604-12.

25. Martinez R, Soliz P, Mujica OJ, Reveiz L, Campbell NRC, Ordunez $\mathrm{P}$. The slowdown in the reduction rate of premature mortality from cardiovascular diseases puts the Americas at risk of achieving SDG 3.4: a population trend analysis of 37 countries from 1990 to 2017. J Clin Hypertens. 2020;22(8):1296-309.

26. Ordunez P, Nieto FJ, Martinez R, Soliz P, Giraldo GP, Mott SA, et al. Chronic kidney disease mortality trends in selected Central America countries, 1997-2013: clues to an epidemic of chronic interstitial nephritis of agricultural communities. J Epidemiol Community Health. 2018;72(4):280-6.

27. Ordunez P, Martinez R, Reveiz L, Chapman E, Saenz C, Soares da Silva A, et al. Chronic kidney disease epidemic in Central America: urgent public health action is needed amid causal uncertainty. PLoS Negl Trop Dis. 2014;8(8).

28. World Health Organization. World report on ageing and health. Geneva: World Health Organization; 2015.

29. Chan JCN, Lim LL, Wareham NJ, Shaw JE, Orchard TJ, Zhang P, et al. The Lancet Commission on diabetes: using data to transform diabetes care and patient lives. Lancet. 2021;396(10267):2019-82.

30. Mitchell S, Malanda B, Damasceno A, Eckel RH, Gaita D, Kotseva K, et al. A roadmap on the prevention of cardiovascular disease among people living with diabetes. Glob Heart. 2019;14(3):215-40.

31. Perel P, Avezum A, Huffman M, Pais P, Rodgers A, Vedanthan R, et al. Reducing premature cardiovascular morbidity and mortality in people with atherosclerotic vascular disease: The World Heart Federation Roadmap for Secondary Prevention of Cardiovascular Disease. Glob Heart. 2015;10(2):99-110. 
32. Batsis JA, Daniel K, Eckstrom E, Goldlist K, Kusz H, Lane D, et al. Promoting healthy aging during COVID-19. J Am Geriatr Soc. 2021;69(3):572-80.

33. Sherrington C, Fairhall N, Wallbank G, Tiedemann A, Michaleff ZA, Howard K, et al. Exercise for preventing falls in older people living in the community: An abridged Cochrane systematic review. Br J Sports Med. 2020;54(15):885-91.

34. Haile LM, Kamenov K, Briant PS, Orji AU, Steinmetz JD, Abdoli A, et al. Hearing loss prevalence and years lived with disability, 1990-2019: findings from the Global Burden of Disease Study 2019. Lancet. 2021;397(10278):996-1009.

35. Davis A, Smith P, Ferguson M, Stephens D, Gianopoulos I. Acceptability, benefit and costs of early screening for hearing disability: A study of potential screening tests and models. Health Technol Assess (Rockv). 2007;11(42):1-294.
36. World Health Organization. Integrated care for older people (ICOPE): guidance for person-centred assessment and pathways in primary care. Geneva: World Health Organization; 2019.

37. Pan American Health Organization. Building health throughout the life course. Concepts, implications, and application in public health. Washington, D.C.: Pan American Health Organization; 2020.

Manuscript received on 29 March 2021. Revised version accepted for publication on 23 July 2021

\section{Esperanza de vida, esperanza de vida saludable y carga de enfermedad en personas mayores en la Región de las Américas desde 1990 hasta el 2019: estudio poblacional}

RESUMEN

Objetivo. Describir la esperanza de vida, la esperanza de vida saludable, la carga de enfermedad y las principales causas de mortalidad y discapacidad en personas adultas de 65 años o más en la Región de las Américas desde 1990 hasta el 2019.

Métodos. Se emplearon estimaciones del estudio sobre la carga mundial de enfermedad del 2019 para examinar las tendencias y el nivel de la esperanza de vida, la esperanza de vida saludable, los años de vida perdidos, los años vividos con discapacidad y los años de vida ajustados en función de la discapacidad (AVAD).

Resultados. En toda la Región, la esperanza de vida a los 65 años aumentó de 17,1 años (intervalos de incertidumbre [IU] del $95 \%$ : 17,0-17,1) en 1990 a 19,2 años (IU del $95 \%$ : 18,9-19,4) en el 2019, mientras que la esperanza de vida saludable se incrementó de 12,2 años (IU del $95 \%$ : 10,9-12,4) a 13,6 años (IU del $95 \%$ : 12,2-14,9). Las tasas de AVAD debida a cualquier causa disminuyeron en cada grupo etario de mayor edad; sin embargo, los AVAD absolutos proporcionales aumentaron de $22 \%$ a $32 \%$. La cardiopatía isquémica, los accidentes cerebrovasculares y la enfermedad pulmonar obstructiva crónica fueron las principales causas de muerte prematura. La diabetes mellitus, la pérdida de la audición relacionada con la edad y de otro tipo, y la lumbalgia fueron las principales causas de discapacidad.

Conclusiones. El aumento de la esperanza de vida y la disminución de los AVAD indican el efecto positivo de las mejoras de las condiciones sociales y las políticas de salud. Sin embargo, el menor aumento de la esperanza de vida saludable indica que, a pesar de vivir más tiempo, las personas pasan una parte sustancial de su vejez con discapacidades y enfermedades. Las enfermedades controlables y prevenibles representan la mayor parte de la carga de enfermedad de las personas mayores en la Región. Se requieren enfoques a escala de toda la sociedad y el curso de vida, y servicios de salud adecuados para responder a las necesidades de salud de las personas mayores en la Región.

Palabras clave Salud del anciano; mortalidad; morbilidad; Américas. 


\section{Expectativa de vida, expectativa de vida saudável e carga de doença nas pessoas idosas nas Américas, 1990-2019: um estudo populacional}

RESUMO Objetivo. Descrever a expectativa de vida, a expectativa de vida saudável, a carga de doenças e as principais causas de mortalidade e incapacidade em adultos a partir dos 65 anos de idade na Região das Américas de 1990 a 2019.

Métodos. Utilizamos estimativas do Estudo de Carga Global da Doença 2019 para examinar o nível e as tendências da expectativa de vida, expectativa de vida saudável, anos de vida perdidos, anos vividos com incapacidade e anos de vida ajustados por incapacidade (AVAI).

Resultados. Em toda a Região, a expectativa de vida aos 65 anos aumentou de 17,1 anos (intervalos de incerteza (II) de 95\%: 17,0-17,1) em 1990 para 19,2 anos (II de 95\%: 18,9-19,4) em 2019, enquanto a expectativa de vida saudável aumentou de 12,2 anos (II de 95\%: 10,9-12,4) para 13,6 anos (II de 95\%: 12,214,9). As taxas de AVAI por todas as causas diminuiu em todos os grupos de pessoas idosas; porém, em termos absolutos, os AVAI proporcionais aumentaram de $22 \%$ para $32 \%$. A cardiopatia isquêmica, o acidente vascular cerebral e a doença pulmonar obstrutiva crônica foram as principais causas de mortalidade precoce. A diabetes melitus, a perda da audição - em função da idade ou por outros motivos - e a dor lombar foram as principais causas de incapacidade.

Conclusão. O aumento da expectativa de vida e a diminuição dos AVAl indicam o impacto positivo das melhorias nas condições sociais e nas políticas de saúde. Porém, o menor aumento na expectativa de vida saudável indica que, apesar de viverem mais, as pessoas passam uma quantidade considerável de tempo na velhice com incapacidade e doença. As doenças preveníveis e controláveis representam a maior parte da carga de doença nas pessoas idosas nas Américas. Abordagens que afetem a sociedade como um todo e o curso de vida, e serviços de saúde adequados, são necessários para atender às necessidades de saúde das pessoas idosas na Região.

Palavras-chave Saúde do idoso; mortalidade; morbidade; América. 